\title{
Metastatic Malignant Neoplasm in Lymph Node
}

National Cancer Institute

\section{Source}

National Cancer Institute. Metastatic Malignant Neoplasm in Lymph Node. NCI

Thesaurus. Code C4904.

The spread of a malignant neoplasm to the lymph nodes. 